Review

\title{
Advanced pediatric diffuse pontine glioma animal models pave the way towards precision medicine
}

\author{
Zirong Chen ${ }^{1}$, Peng Peng', Xiaolin Zhang ${ }^{1}$, Barbara Mania-Farnell ${ }^{2}$, Guifa $\mathrm{Xi}^{3{ }^{*}}$ and Feng \\ Wan $^{1, *}$
}

${ }^{1}$ Department of Neurological Surgery, Tongji Hospital, Tongji Medical College, Huazhong University Science and Technology, Wuhan, 430030 China; czrong718@163.com (Z.C.); pengdoctor215@gmail.com (P.P.); zx196718@163.com (X.Z.); wanruiyan@hotmail.com (F.W.)

${ }^{2}$ Department of Biological Science, Purdue University Northwest, Hammond, IN, 46323 USA;

bmania@pnw.edu

${ }^{3}$ Department of Neurological Surgery, Northwestern University Feinberg School of Medicine, Chicago,

IL, 60611 USA; guifa.xi@northwestern.edu

* Correspondence: G.X., guifa.xi@northwestern.edu; +01(312)5034296, and F.W.,

wanruiyan@hotmail.com; +01 (027)-8366-5201.

\begin{abstract}
Diffuse intrinsic pontine gliomas (DIPGs) account for $\sim 15 \%$ of pediatric brain tumors, which invariably present with poor survival regardless of treatment mode. Several seminal studies have revealed that $80 \%$ of DIPGs harbor H3K27M mutation coded by HIST1H3B, HIST1H3C and H3F3A genes. The H3K27M mutation has broad effects on gene expression and is considered a tumor driver. Determination of the effects of H3K27M on posttranslational histone modifications and gene regulations in DIPG is critical for identifying effective therapeutic targets. Advanced animal models play critical roles in translating these cuttingedge findings into clinical trial development. Here, we review current molecular research progress associated with DIPG. We also summarize DIPG animal models, highlighting novel genomic engineered mouse models (GEMMs) and innovative humanized DIPG mouse models. These models will pave the way towards personalized precision medicine for the treatment of DIPGs.
\end{abstract}

Keywords: Diffuse intrinsic pontine glioma; molecular biology; patient derived xenografts; genetically engineered mouse model; humanized mouse model

\section{Introduction}

Diffuse intrinsic pontine glioma (DIPG), a high-grade glioma that arises in the pons is exclusively seen in children. This central nervous system (CNS) malignancy represents the leading cause of brain-tumor related death [1]. Ionizing radiation therapy extends overall survival to a median of 11 months [2]. Numerous clinical trials have failed to identify effective agents, or therapeutic combinations against DIPG [3]. A key to identifying improved treatments is to enhance our biological understanding of this tumor.

DIPG molecular signature has been profiled over the last decade. Landmark studies from multiple groups identified an epigenetic oncogenic histone H3K27M mutation in $\sim 80 \%$ of DIPGs [4-6]. This mutation was defined as a new entity labeled "diffuse midline glioma H3K27M-mutant" in the 2016 CNS tumor classification [7]. A number of molecular aberrations, which are potential targets for treatment have been identified. They include RB phosphorylation [8], P53, Wee1, STAT3, PPM1D and EGFRvIII overexpression [9-13], plateletderived growth factor receptor A (PDGFRA) and MET amplification [8,14], and ACVR1 [1518], PI3K-mTOR or -MAPK activation [8]. These aberrations are either independent or concurrent with H3K27M mutations in DIPGs. More recently, multiple pathways, such as 
Notch signaling [19], glycolysis and tricarboxylic acid (TCA) metabolic pathways [20], Wilms' tumor protein (WT1) overexpression [21,22] and FGFR2-VPS35 fusion [23] were delineated. These pathways are also potential therapeutic targets. Altogether, these abnormalities indicate the molecular complexity of DIPGs. Thus, to identify effective targeting therapeutics or combinations of such, reliable and personalized animal models are desirable for precise preclinical evaluation prior to clinical trials.

Various animal models have been developed for the identification of potential therapeutics against DIPGs. One reason for this development was that historically, surgical biopsies for DIPGs were not performed due to the critical nature of the brainstem, limitations of surgical techniques and histological heterogeneity within the tumor [24]. Multiple murine gliomas induced with various carcinogens were transplanted, so called "allografts", into the brainstem as models for DIPGs [25]. The results from these models, however, failed to translate into clinical trials due to differences in tumorigenesis mechanisms between these murine gliomas and DIPGs in children. Recently, several groups have safely performed biopsies and obtained tumor specimens from DIPG patients [26]. Moreover, adequate autopsy DIPG specimens have been obtained for experimental purposes. With availability of these invaluable specimens, more accurate patient-derived orthotopic xenograft (PDOX) DIPG mouse models were and continue to be generated for pre-clinical therapeutic testing [27-29]. More importantly, these specimens helped generate multiple cell-based models, which have provided significant insights into genetic and epigenetic alterations driving DIPGs. These insights, in conjunction with current cutting-edge gene editing techniques, have allowed and prompted scientists to generate robust genetically engineered mouse models (GEMMs), to understand DIPG tumorigenesis and to provide precise molecular models for pre-clinical testing. One caveat is that the majority of xenograft models are produced in immunodeficient athymic or NOD-SCID gamma (NSG) mice, which lack normal immunity. Consequently, these mouse models do not mimic the human tumor microenvironment including infiltration by immune cells. Recent work has shown that immune cells discovered in pediatric DIPG tumor specimens are distinct and differ from those in adult glioblastomas [30]. Generation of humanized DIPG mouse models is urgently needed to explore these differences, an understanding of which will accelerate therapeutic discovery.

In this review, we summarize current research on DIPG molecular profiling and DIPG animal models, with emphasis on innovative GEMMs and humanized mouse models. We also discuss the potential for of advanced personalized humanized models for pre-clinical therapeutic evaluation, which will pave the way towards personalized precision medicine for DIPG treatment.

\section{Molecular characteristics of DIPG}

Diffuse intrinsic pontine glioma (DIPG) was identified in 1926 [31]. For decades, its biological behavior was believed to be similar to adult malignant gliomas, thus therapeutic regimens for adult tumors were copied in children. These treatments failed to improve patient outcomes [3], which led researchers to ask if pediatric malignant gliomas including DIPGs fundamentally differ from adult gliomas. Unfortunately, surgical resection or biopsy was not a standard procedure, therefore it was a challenge to obtain adequate tumor tissue for analysis of biological characteristics.

Recently several groups have developed safe and feasible methods to collect biopsy tissue samples from pediatric DIPG patients with minimum mortality [26,32]. Furthermore, autopsy samples can be acquired for either direct molecular profiling or development of patient-derived primary cell lines and/or xenografts to gain insight into tumor driving mechanisms [33]. These tissues sources, as well as high-throughput genetic technologies enabled researchers to acquire data, which provided insight into DIPG molecular signatures. For instance, recurrent amplifications of PDGFRA, MET and retinoblastoma protein (RB) are unique for pediatric 
DIPG $[8,34]$. These findings prove that DIPG is molecularly distinct from adult malignant gliomas. Other groups using high-throughput genetic sequencing technologies have identified that $\sim 80 \%$ of DIPGs contain somatic point heterozygous H3.1K27M or H3.3K27M mutations [46], recognized to be major oncogenic drivers in these tumors $[6,35,36]$.

DIPGs with H3.1K27M or H3.3K27M mutations, coded by HIST1H3B, HIST1H3C and H3F3A, respectively [37] have different clinical manifestations and gene expression profiles. H3.1K27M tumors are usually restricted to the pons and show a mesenchymal-like phenotype. Hypoxia and angiogenesis associated genes are overexpressed in these tumors, and patient survival time is longer. Tumors with H3.3K27 mutation are found in the pons and other midline locations such as the thalamus [38]. These tumors display an oligodendroglial-like phenotype, are more resistant to radiation therapy and result in shorter median patient survival time [39]. Full function of these two mutations remains unclear, however, both H3.1K27M and H3.3K27M mutations primarily impact the epigenome and are required for DIPG tumorigenesis and maintenance $[40,41]$. These mutations predominantly reduce genome-wide levels of repressive H3K27me3 [37,42,43] through inactivation of Polycomb Repressive Complex 2 (PRC2) [44]. Further studies have confirmed that H3K27M suppresses PRC2 through tight binding to EZH2, a core PRC2 subunit [45]. H3K27me3 levels are differentially associated with H3.1K27M or H3.3K27M mutations, with H3.3K27M epigenome maintaining some H3K27me3, while H3.1K27M almost completely excludes genomic-wide H3K27me3 [46]. Moreover, H3K27M DIPG shows slightly elevated H3K27ac [44,47,48], which colocalizes with H3K27M mutations at enhancer or promoter areas [44]. In turn, their co-localization results in differential euchromatin and heterochromatin status and thus gene expression. Multiple pre-clinical therapeutic evaluations have shown that inhibition of histone deacetylases is effective and has survival benefits in DIPG xenograft animal models [49], indicating therapeutic potential targeting H3K27ac in H3K27M mutant DIPGs. Interestingly, methylation on other $\mathrm{H} 3$ histone residues including $\mathrm{K} 4$ and $\mathrm{K} 9$ is relatively unaffected [50,51]. For instance, H3K27me3 and H3K4me3 are the most common bivalent histone marks in mammalian cells covering $\sim 20 \%$ of the genome [52], however, global H3K4me3 level is relatively stable regardless of histone H3 mutation [41]. The underlining mechanisms are still under investigation. More recently, H3K36me2 and H4K16ac were identified as important histone marks in DIPGs [53], however, their biological function needs to be identified.

In addition to epigenomic alterations in H3K27M mutant DIPG, numerous aberrations of gene expression, DNA copy number variations and signal pathways have been uncovered. These may occur concurrently or independently with H3K27M mutation. p38 MAPK is activated in both H3.3K27M and H3.1K27M cultured cells with H3.1K27M tumor cells more sensitive to p38 MAPK inhibition [48]. WNT [48,54], mTOR [54,55] and RTK-RAS-PI3K signaling pathways [54,56] were also active in both tumor subtypes. Interestingly, H3.1K27M and H3.3K27M DIPGs have their own associated mutations (Figure 1). For instance, ACVR1 and PIK3CA mutations are usually associated with H3.1K27M [17,57], while PDGFRA, MYC, CCND2 amplifications and TP53 and PPM1D mutations are found in H3.3K27M DIPGs [4,57]. H3.3K27M mutations enhance glycolysis tricarboxylic acid cycle metabolism to produce $\alpha-\mathrm{KG}$, which is required to maintain a preferred epigenetic state of low H3K27me3 [20]. With integrative genetic, epigenetic and proteomic analysis, intrinsic molecular heterogeneity and tumors with rare subpopulations [58] are expected to be uncovered and will expand our 
understanding of DIPGs.

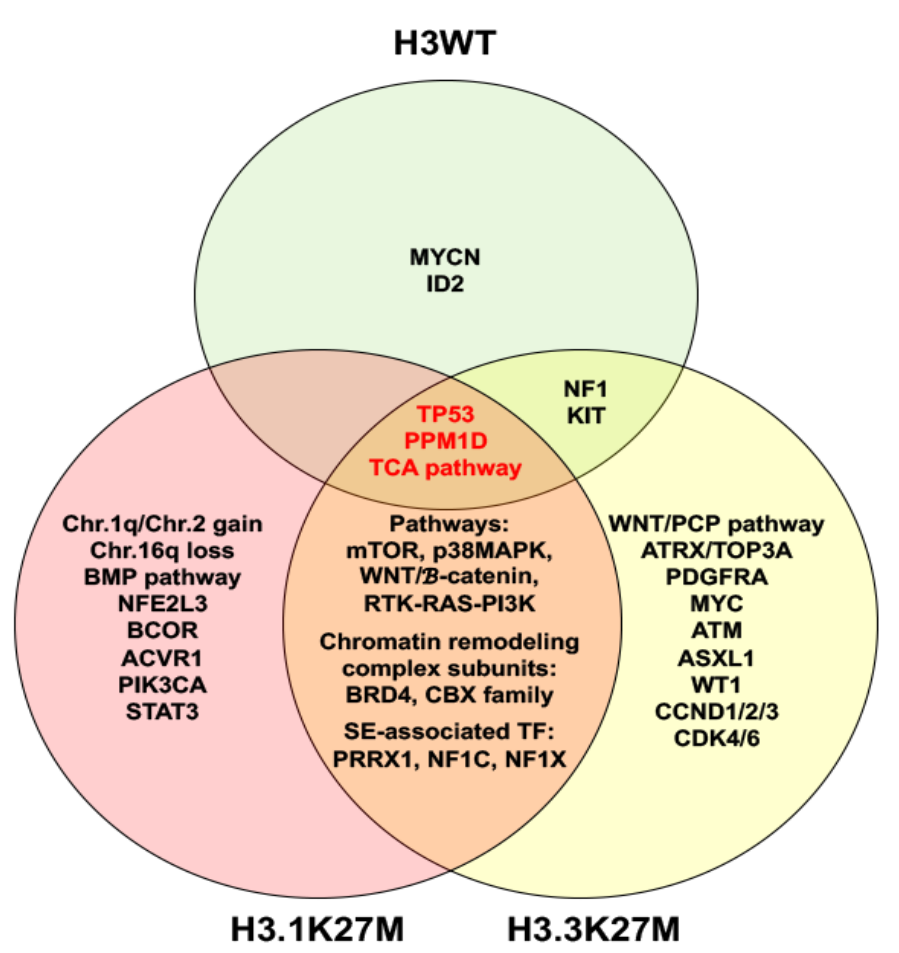

Figure 1. Venn diagram illustrates molecular characteristics of histone $\mathrm{H} 3$ wild type (H3WT), H3.1K27M and H3.3K27M diffuse intrinsic pontine gliomas. Abbreviation: TCA, tricarboxylic acid.

The diversity in genetics, chromatin landscape and metabolic reprogramming of DIPGs clearly shows that individualized therapeutics will be critical for effective treatments. To this end, developing personalized animal models for pre-clinical assessment is an important step to identify and determine the best therapeutic agents.

\section{Murine models of DIPG}

Animal models for brain tumors are critical for understanding potential mechanisms and to assess the efficacy of novel therapeutic molecules or compounds for clinical application. Several species including zebrafish [59], rats [60,61], mice [62-64], dogs [65], hamsters [66], monkeys [67] and non-human primates [68] have been used to develop brain tumor models. Murine is the most popular animal because they are easy to handle and manipulate and have a short lifespan. Thus, here we focus on summarizing murine brainstem tumor models that expand biological understanding of DIPG.

\subsection{Synergetic allograft brainstem glioma models}

The first animal models for brainstem glioma were developed in rats. Rat glioma F98 and 9L cells were implanted using a stereotactic head frame [62]. Following this study, multiple rat synergetic cell lines including C6, F98, 9L with or without luciferase modification were inoculated into the brainstem of neonatal or adult rats to generate brainstem tumor models [25,60,69-71]. These models were developed using stereotactic head frames targeting the pons (Figure 2A). Experimental rats developed pontine tumors, with appropriate location and microenvironment. However, most of these cell lines were developed from cerebral cortical tumors and heavily passaged in culture [61], thus they were not the best model to represent biological behavior of childhood DIPGs. These models are now being replaced by xenograft 
models using human DIPG cells directly from biopsy or primary culture [72].

\section{A. Allograft DIPG mouse model}

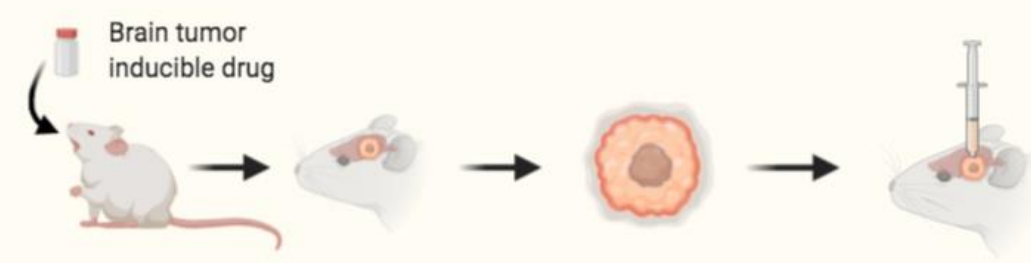

B Patient derived xenograft DIPG mouse model

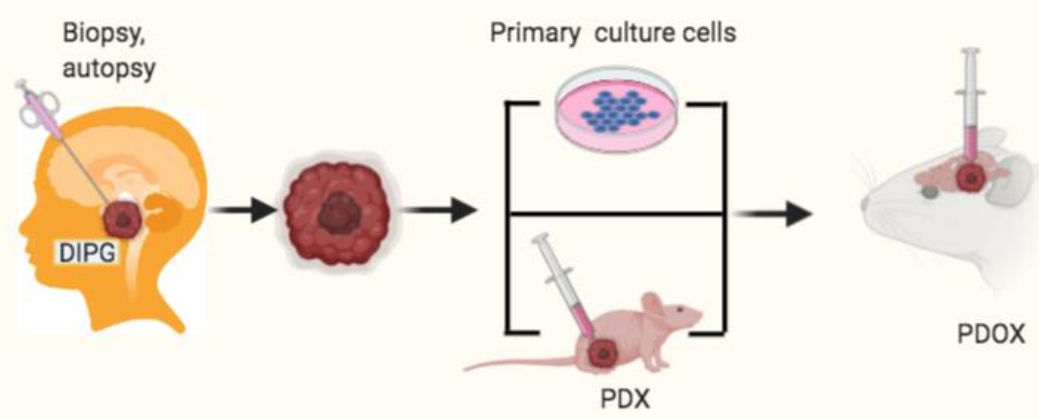

Figure 2. Schematic diagrams illustrate the development of allograft (A) and patient derived xenograft (B) mouse models for DIPG.

\subsection{Patient-derived orthotopic xenograft (PDOX) DIPG mouse models}

Human glioblastoma (GBM) xenografts were developed in mouse or rat brainstem as models for DIPG $[63,73]$. Adult GBM cells including U87, U251MG and GS2 were inoculated into the pons using a stereotactic headframe to develop brainstem tumors for therapeutic testing. In these studies, brainstem microenvironment and blood-brain barrier were taken into consideration, however, as most of these cell lines were derived from adult cerebral cortical GBM biological features of DIPG were ignored. A few studies with ionizing irradiation, which is standard care for pediatric DIPG, were tested using these models and showed temporary efficacy [28]. However, other therapeutic tests did not show efficacy in multiple clinical trials. For instance, temozolomide, a DNA methylation agent for adult GBM treatment, and PD0332991, a CDK4/6 inhibitor were reported effective in murine brainstem models using adult GBM cell lines $[63,64,74]$, however, clinical trials using TMZ and CDK4/6 inhibitor did not markedly extend survival for children with DIPG $[75,76]$. These findings indicate that glioma cells from adult tissue and from non-pontine locations are not suitable for predicting DIPG therapeutic response.

Due to limitations of the models discussed above, human DIPG cells obtained from autopsy and biopsy samples were developed. These cell sources provided new biological insights into DIPG molecular characteristics, and were key in moving forward the development of patientderived orthotopic xenograft (PDOX) DIPG models. The first pediatric DIPG in vitro cell culture and in vivo xenograft mouse models were developed using early postmortem tumor tissue [77], in which pontine histopathology was similar to that of DIPG. Following this work, primary cultured cells from DIPG biopsy specimens and an orthotopic mouse model using these cells were successfully developed [73]. These pioneer studies led to the development of numerous primary cultured DIPG cells and PDOX models for testing novel therapeutics (Figure 2B). Recent studies have shown that promoter H3K27Ac is elevated in DIPG with H3K27M mutation [44,47]. Several PDOX models for DIPG were used to test panobinostat, a histone acetylation inhibitor, which showed promising results $[47,78]$. Excitingly, panobinostat has been registered in multiple clinical trials for DIPG (NCT02717455, NCT04341311, 
NCT03566199). In addition to panobinostat, more compounds and novel small molecules have been tested in various DIPG PDOX models as summarized in Table 1.

Table 1. Patient derived DIPG cell lines for in vitro culture and for in vivo generation of orthotopic mouse models.

\begin{tabular}{|c|c|c|c|}
\hline $\begin{array}{l}\text { Cell } \\
\text { source }\end{array}$ & $\begin{array}{l}\mathrm{H} 3 \\
\text { mutation }\end{array}$ & Name of cell line & Novel therapeutic compounds tested \\
\hline \multirow[t]{4}{*}{ Autopsy } & H3WT & $\begin{array}{l}\text { VUMC-DIPG-10 [79], DIPGM(T) } \\
{[77,80]}\end{array}$ & $\begin{array}{l}\text { OTSSP167 [79], veliparib, olaparib, niraparib } \\
{[80]}\end{array}$ \\
\hline & $\mathrm{H} 3.1 \mathrm{~K} 27 \mathrm{M}$ & SU-DIPG-IV [17,44,80-85] & $\begin{array}{l}\text { LDN212854 [17], JQ1 [44], Panobinostat, GSK- } \\
\text { J4 [84], veliparib, olaparib, niraparib [80], Corin } \\
\text { [83], PTC-209 [85] }\end{array}$ \\
\hline & H3.3К27M & JHH-DIPG1 (T) $[19,55,79,84,86,87]$ & $\begin{array}{l}\text { Delta-24-RGD [86], TMZ [87], GSK-J4 [84], } \\
\text { Panobinostat, OTSSP167 [79], TAK228 [55], } \\
\text { MRK003 [19] }\end{array}$ \\
\hline & & $\begin{array}{l}\text { SU-DIPG-VI(T) } \quad[88], \quad \text { XIII, } \\
\text { XVII[55,81-83,89] }[19,84,85,90]\end{array}$ & $\begin{array}{l}\text { LDN-193189, LDN-214117, LDN-212854 [82], } \\
\text { TAK228 [55], 6-thio-Dg [89], BGB324 [90], } \\
\text { Panobinostat [84], GSK-J4 [84], Corin [83], } \\
\text { MRK003 [19], PTC-209 [85] }\end{array}$ \\
\hline \multirow[t]{10}{*}{ Biopsy } & H3WT & CCHMC-DIPG-1 (T) [85,89] & PTC-209 [85], 6-thio-Dg [89] \\
\hline & H3.1K27M & HSJD-DIPG-018 [82] & GSK343 [91], EPZ6438 [91] \\
\hline & & VUMC-DIPG-B [84] & Panobinostat, GSK-J4 [84] \\
\hline & H3.3K27M & $\begin{array}{l}\text { SF8628 (T) }[13,17,44,92], \text { SF7761 } \\
{[19,44,55,84,87,90,93]}\end{array}$ & $\begin{array}{l}\text { TAK228 [55], MK-1775 [13], JQ1 [44], TMZ [87], } \\
\text { Panobinostat, GSK-J4 [84,93], BGB324 [90], } \\
\text { CUDC-907 [92], MRK003 [19], GSK343 [91], } \\
\text { EPZ6438 [91] }\end{array}$ \\
\hline & & $\begin{array}{l}\text { HSJD-DIPG-007 (T) [82], 008, 012, } \\
014 \text { [81-83,90,93-95] }\end{array}$ & $\begin{array}{l}\text { Bevacizumab [95], OTSSP167 [79], BGB324 [90], } \\
\text { Panobinostat [94], LDN-193189, LDN-214117, } \\
\text { LDN-212854 [82], GSK343, EPZ6438 [91], Corin } \\
\text { [83] }\end{array}$ \\
\hline & & $\begin{array}{l}\text { VUMC-DIPG-A (T) [84,90] [79], F } \\
\text { [91] }\end{array}$ & OTSSP167 [79], BGB324 [90], Panobinostat [84] \\
\hline & & TP54, 80 (T) [86], TP83, 84[86] & Delta-24-RGD [86] \\
\hline & & NEM 157, 163, 165, 168 [84] & Panobinostat, GSK-J4 [84], Delta-24-RGD [86] * \\
\hline & & QCTB-R059 [82], CHRU-TC68 [16] & LDN-193189, LDN-214117, LDN-212854 [16,82] \\
\hline & & CCHMC-DIPG-2 [85] & PTC-209 [85] \\
\hline
\end{tabular}

Note. T: tumorigenic; OTSSP167: MELK inhibitor; LDN212854, LDN-193189, LDN-214117: BMP receptor inhibitor; GSK-J4: KDM6B-specific inhibitor; PTC-209: BMI-1 inhibitor; TMZ: Temozolomide; TAK228: oral dual TORC1/2 inhibitor; MRK003: $\gamma$-secretase inhibitor; BGB324: Bemcentinib; GSK343: EZH2 inhibitor; EPZ6438: Tazemetostat; MK-1775: Adavosertib; JQ1: BET bromodomain inhibitor; CUDC-907: dual PI3K and HDAC inhibitor; * clinical trial

Overall, stereotactic biopsy of DIPG is considered safe and effective [96,97], and techniques to develop primary cell cultures and orthotopic DIPG models from autopsy specimens have improved. This has led to the development of PDOX mouse models with primary cultured DIPG cells. These models will help identify effective therapeutic pharmaceutical agents or compounds for clinical trials.

\subsection{Genetically engineered mouse models (GEMMs) for DIPG}

Xenograft models cannot answer some fundamental questions, for instance, i) what cells does DIPG originate from? ii) is a specific genetic or epigenetic alteration sufficient to drive 
DIPG formation? and iii) what role do oncogenes or tumor suppressors play in DIPG tumorigenesis? Genetically engineered mouse models (GEMMs) can be used to help answer these critical questions.

GEMMs are ideal to investigate DIPG cell origin for insight into tumorigenesis mechanisms. Several systems, including replication-competent avian sarcoma-leukosis virus long terminal repeat splice acceptor (RCAS/Tv-a) (Figure 3A), Sleeping Beauty/PiggyBac

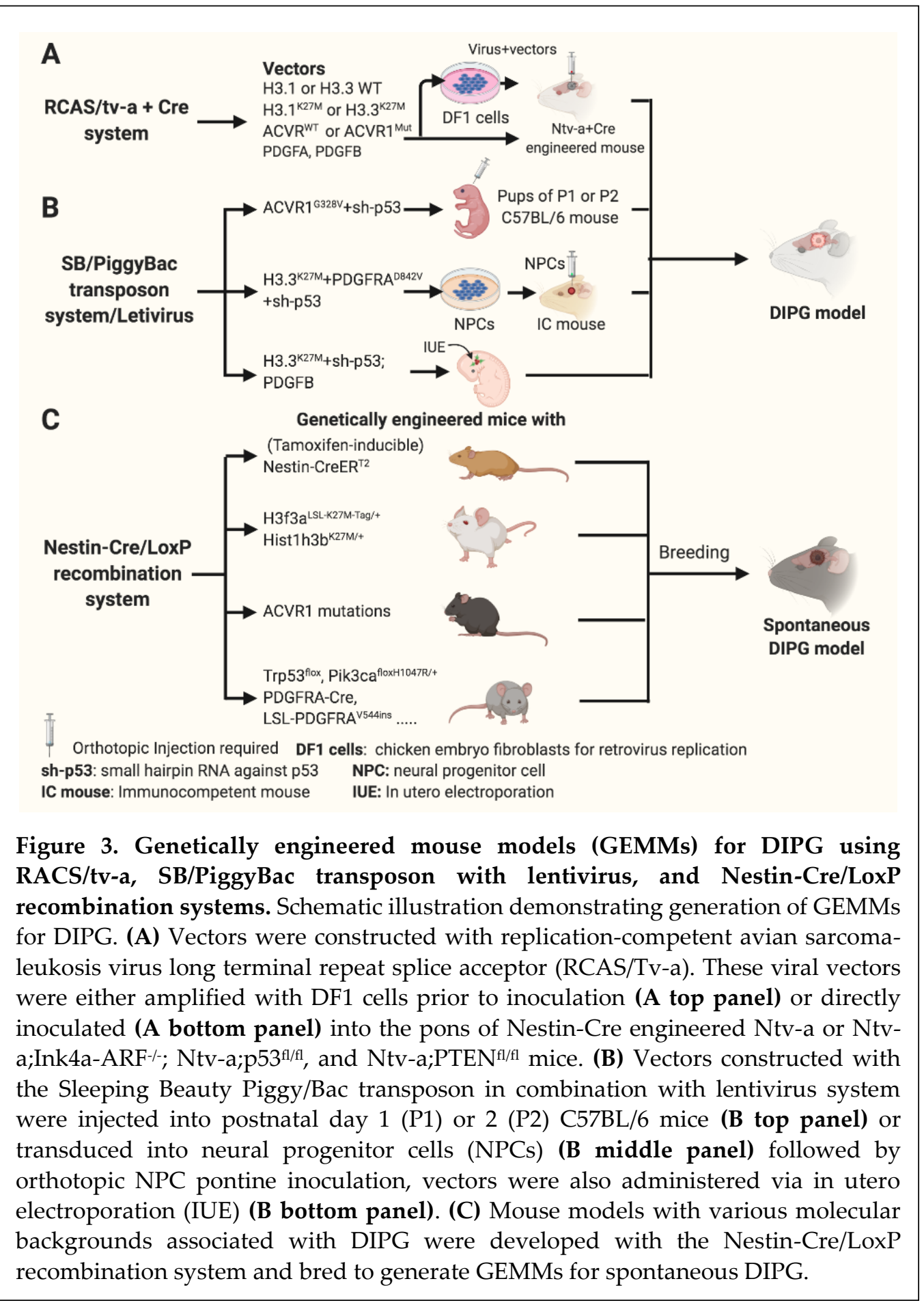

transposon in combination with lentivirus (Figure 3B) and Nestin-Cre/LoxP recombination (Figure 3C) systems have been utilized to generate multiple GEMMs. GEMMs developed with these systems can be used to investigate potential populations of cells from which DIPG can 
originate including: nestin-expressing progenitor cells (Nestin+/Vimentin $\left.+\mathrm{Olig}^{+}\right)$[77]; oligodendrocyte progenitor cells (Olig2 ${ }^{+} / \mathrm{Sox}^{+} / \mathrm{APC}$ ) [98]; and at least two distinct types of Pax3- expressing progenitor cells (immature $\mathrm{Pax}^{+} / \mathrm{Nestin}^{+} / \mathrm{Sox}^{+}$progenitor and differentiated $\mathrm{Pax3}^{+} / \mathrm{NeuN}^{+}$neuron) [99]. In addition to these GEMMs, nestin positive progenitor cells which line the floor of the fourth ventricle genetically engineered with ectopic PDGFB, p53 loss and with or without the H3.3K27M mutation with the RCAS/Tv-a system (Figure 3A), were also shown to have biological similarity with DIPG $[37,100,101]$. Given the facst that the majority of human DIPGs are believed to arise from the ventral pons, and its tumorigenesis is complicated and regulated by dynamic tempo-spatial genomic and epigenomic events, cell origin for DIPG is an essential question which has yet to be answered.

GEMMs are robust tools to identify tumor drivers. Somatic point heterozygous mutation on HIST1H3B or H3F3A and multiple deregulations of genes such as p53, PDGFB, PDGFRA, AVCR1 are important genomic alterations. While HIST1H3B or H3F3A which codes for the H3K27M mutation was initially considered a tumor driver, human embryonic stem cell derived neural progenitor cells (hES-NPCs) transformed using a combination of lentivirus encoding H3.3K27M did not form tumors in mouse pons. hES-NPCs engineered with H3K27M, p53 loss and PDGFB mutation formed tumors in mouse pons, with biological characteristics comparable to DIPG [102]. Another GEMM which formed brainstem tumors with biological characteristics similar to DIPG, was created via in utero electroporation to deliver Piggy/Bac transposable-H3.3K27M, Trp53 CRISPR/Cas9 and PDGFRA into the lower rhombic lip of NPCs in vivo (Figure 3B) [103]. Recently, a novel inducible GEMM was developed in which H3.3K27M was transduced into an H3F3A locus in combination with loss of p53 and a PDGFRA mutant. This combination was driven by a tamoxifen-inducible Cre recombinase in neonatal nestin-positive cells throughout the developing brain (Figure 3C) and formed spontaneous malignant brain tumors, which mimic H3.3K27M DIPG [104]. Using a similar approach, H3.1K27M and ACVR1G328V were knocked into their respective loci driven by Cre recombinase in Oligo2 ${ }^{+}$oligodendrocyte precursor cells (OPCs). These genetically engineered cells showed glial differentiation arrest and high proliferation, but were insufficient to drive tumor formation. However, spontaneous high-grade gliomas were formed in the brainstem and thalamus if additional endogenous PIK3CAH1047R was knocked in [15]. These GEMMs indicate that the onco-histone mutation of $\mathrm{H} 3.1 \mathrm{~K} 27 \mathrm{M}$ or $\mathrm{H} 3.3 \mathrm{~K} 27 \mathrm{M}$ in combination with PDGFRA, p53 loss, PDGFB, ACVR1 mutation have a synergistic effect on driving DIPG.

Numerous dynamic genomic and epigenomic alterations contribute to DIPG tumorigenesis. GEMMs can be used to identify therapeutics that target for specific gene alterations or combinations of changes. For instance, a high-grade brainstem glioma was generated by overexpression of PDGFB in combination with Ink4a-ARF loss in the posterior fossa of neonatal Nestin Tv-a mice. This model was used to test perifosine, an AKT inhibitor and irradiation [101]. The model was also used to test PD-0332991 (PD), a CDK4/6 inhibitor, which did prolong survival [100]. Another GEMM for DIPG driven by PDGF-B, H3.3K27M, and p53 loss using the RCAS/tv-a system was developed to test BMS-754807, a potent and reversible small molecule multi-kinase inhibitor, which showed significant efficacy in vitro [105]. A GEMM model of hESNPCs engineered with H3K27M, p53 loss and PDGFB mutation was used to test menin inhibitor MI-2, which showed significant efficacy in decreasing tumor growth [103].

In all, GEMMs for DIPG are an important supplement to PDOX for investigation of tumorigenesis mechanisms, to determine cell origin and to test novel therapeutic compounds. However, GEMMs generally focus on a few genes, only represent tumors with engineered backgrounds and lack heterogeneity of patient tumor samples. Due to the differential tumor microenvironment between mice and humans, tumor biological behavior may differ from original human DIPGs. Thus, precise DIPG animal models which incorporate human immunity must be developed. 


\section{Humanized mouse models for DIPG precision medicine}

Recently, serval studies have shown that the tumor immune microenvironment (TIME) has critical roles in DIPG: i) Tumor-infiltrating cells (TILs) including Treg, CD4 T cells, NK, B cells, monocytes and eosinophils have been identified in H3K27M mutant DIPGs [106]; ii) Expression of indoleamine 2,3 dioxygenase 1 (IDO1), an immunosuppressive enzyme that metabolizes tryptophan, is low in cultured DIPG cells. However, in vitro induction of IDO1 with IFN $\gamma$ showed potential therapeutic value [107]; iii) the disialoganglioside GD2 is highly expressed in patient-derived H3K27M mutant glioma cell cultures. Anti-GD2 CAR T cells incorporating a 4$1 \mathrm{BBz}$ costimulatory domain demonstrated robust antigen-dependent cytokine generation and killed DIPG cells in vitro [108] and iv) a humanized anti-CD47 antibody, Hu5F9-G4, demonstrated therapeutic efficacy [109].

These cutting-edge findings require testing using reliable animal models prior to translation into clinical trials. For many years, chimpanzees were used to bridge the gap between rodent models and humans. However, the biomedical use of chimpanzees is prohibited in Europe and the United States. Therefore, to overcome the limitations of translating laboratory rodent discoveries into clinical applications, development of mouse models that closely recapitulate human biological systems, labeled as "humanized" mice is critical for pre-clinical investigation. In this section, we will discuss recent progress in the development and potential use of humanized DIPG mouse models.

Humanized mice are defined as immunodeficient mice engrafted with human tissues [110]. Discovery of nude mice in the 1960s and severe combined immunodeficient (SCID) mice in the 1980s [111] were key advances for xenografts. Following these models, nonobese diabetic (NOD)/SCID and NOD/SCID $/ \beta 2 \mathrm{~m}^{\text {null }}$ and $\mathrm{NOD} / \mathrm{Rag} 1^{\text {null }} \mathrm{Pf} \mathrm{p}^{\text {null }}$ mice were subsequently

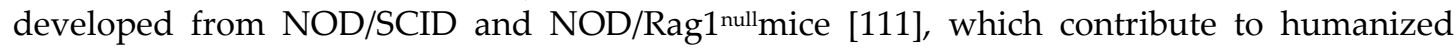
mouse generation. Another landmark advance in the generation of humanized mice was the generation of NOD/SCID $/ \gamma \mathrm{c}^{\text {null }}$ mice and $\operatorname{Rag} 1 / 2^{\text {null }} \gamma \mathrm{c}^{\text {null }}$ mice through introducing IL2ra into NOD/SCID and RAG1/2\% mice in the 2000s [111]. These mice show multiple

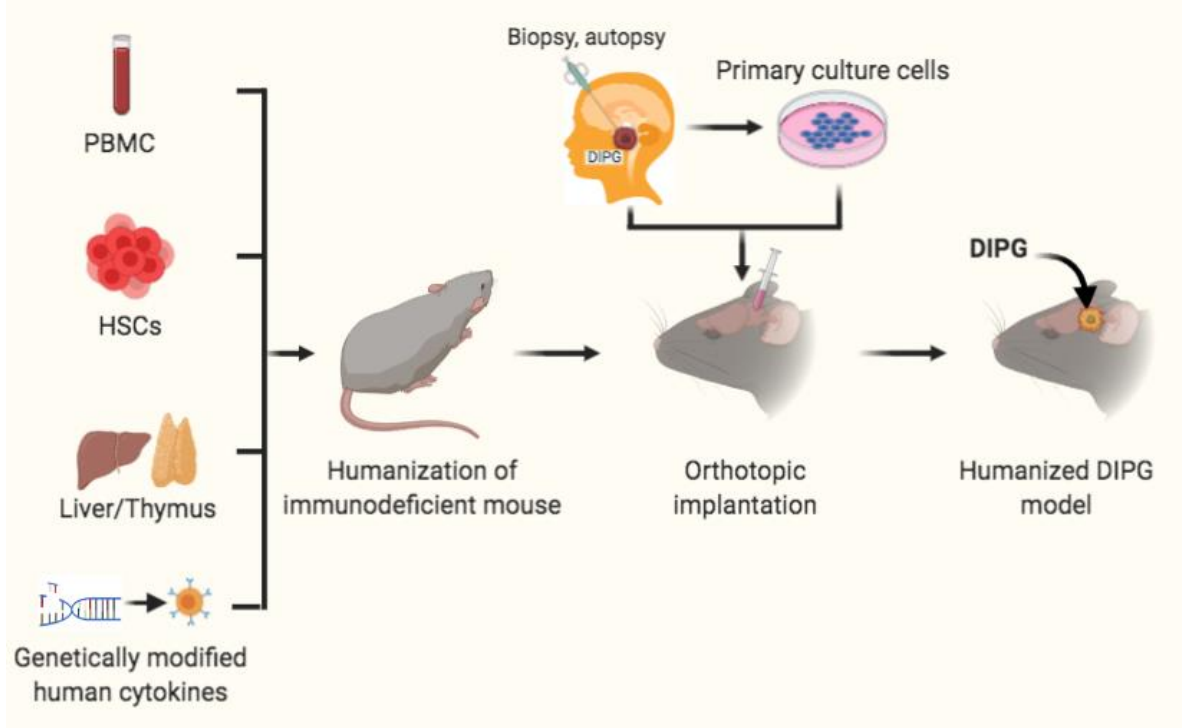

Figure 4. Humanized mouse models for DIPG. Immunodeficient mice received peripheral blood mononuclear cells (PBMCs), or hematopoietic stem cells (HSCs) and transplantation of liver/thymus, or genetically modified human cytokines prior to orthotopic intracranial inoculation of DIPG cells, from patient biopsy or autopsy specimens or primary cultured cells, into the pons to develop humanized DIPG models. 
immunodeficiencies including impaired T, B and nature killer (NK) cells, and reduced macrophages and dendritic cell immune function, and a high rate of human cell including DIPG engraftment. Recently, several humanized mouse models were used to test novel

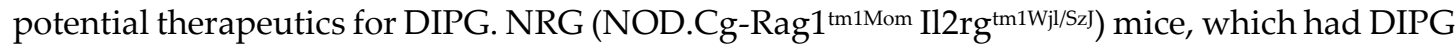
cells implanted in the pons, were used to test therapeutic efficacy of a DNA-damaging reagent 6-thio-2'deoxyguanosine (6-thio-dG). The results demonstrated promising therapeutic efficacy [89]. NOD-SCID $\gamma$ (NSG) mice were used to test anti-CD47 antibody Hu5F9-G4 through orthotopic injection of several DIPG cells. The results showed intraperitoneal treatment with this antibody significantly reduced tumor growth and increased survival benefit [109]. NSG NOD-SCID IL2 $\mathrm{rg}^{-/}$(NSG) mice were used for testing anti-GD2 CAR-T cell immunotherapy [108], with the results leading to an active clinical trial (NCT04196413).

Humanized mice are also defined as immunodeficient mice engrafted with hematopoietic cells $[110,111]$. There are several strategies for establishment of these humanized mouse models (Figure 4). The first one is humanized mice receiving human peripheral blood mononuclear cells (PBMCs) engrafted to establish the Hu-PBL-SCID model. This model is suitable for shortterm research and investigation of the relationship between immune function of lymphocytes in peripheral blood and tumor biological behavior [112]. The second strategy is the transfer of human hematopoietic stem cells (HSCs) into mice with the IL-2r $\gamma^{\text {null }}$ mutation to develop the Hu-SRC-SCID model [113]. HSCs can be obtained from granulocyte colony-stimulating factormobilized PBMCs, adult bone marrow, fetal liver and umbilical cord [114]. This model also supports engraftment of complete human immune system through injection of CD34+ ${ }^{+} \mathrm{HSCs}$ (Hu-CD34+ model), which is appropriate for investigating tumor growth and immune system development [115]. The third model is a bone marrow/ liver/ thymus (BLT) model which is developed via transplanting human fetal liver and thymus under the kidney capsule. More recently, a novel and revolutionary humanized mouse model NOD-SCID IL2rgnull SCF/GMCSF/IL3 strain engrafted with human thymus, liver, and hematopoietic stem cells (termed Bone marrow, Liver, Thymus [BLT]) (NSG-SGM3-BLT) was used to develop an orthotopic model through injection of SF8628, a H3.3K27M mutant cell in the pons, to test IDO1 induction by $\mathrm{CD}^{+}$and $\mathrm{CD} 8^{+} \mathrm{T}$ cells. The results showed that these $\mathrm{T}$ cells directly increase IDO1 expression in intracranial DIPG tumor and are thus a promising adjuvant immunotherapy [107].

In addition, mice transgenically engineered to express human genes are also human ized mice. One example is MISTRG mice, in which seven genes including M-CSFh/h IL-3/GM$\mathrm{CSF}^{\mathrm{h} / \mathrm{h}} \mathrm{SIRPa}^{\mathrm{h} / \mathrm{h}} \mathrm{TPO}^{\mathrm{h} / \mathrm{h}} \mathrm{RAG2}{ }^{-/}$IL2Rg-/ were knocked into mouse genomic loci [116]. MISTRG mice are humanized with high immunodeficiency, which prevents immune rejection of the human grafts. These mice are a robust tool to investigate engrafted tumors and innate immune response, which is potentially useful for the development of humanized DIPG models.

Altogether, these advanced humanized mouse models provide a more realistic human tumor immune microenvironment with potential for better drug response and prediction for clinical trials and will help to identify effective therapeutic regimens for DIPG.

\section{Summary and prospective}

In summary, we review up-to-date genomic and epigenomic profiling advances in DIPG. In addition to H3K27M mutation, numerous aberrations of gene expression, DNA copy number variations, abnormal signal pathways and posttranslational histone modifications also contribute to DIPG tumor biology. This highlights the complexity and challenges of identifying effective therapeutics for individual patients. We also summarize mouse models for DIPG with specific emphasize on GEMMs and recent innovative humanized mouse models. We believe, because of rapid advances in biological techniques such as high-throughput proteomics analysis, next-generation and single cell sequencing, advanced gene-editing tools etc., more novel molecules or signal pathways and epigenetic factors as potential therapeutic targets will be identified. Testing these targets in novel GEMMs and innovative humanized mouse models, 
will pave the way to precision medicine necessary for effective treatment, and dramatically improve outcomes for children with these tumors.

Author Contributions: Conceptualization, Z.C., G.X., and F. W.; writing-original draft preparation, Z.C., P.P., X.Z., and G.X.; writing - review and editing, B. M-F., G.X., and F.W. All authors have read and agreed to the published version of this manuscript

Funding: This work was funded by NATIONAL NATURAL SCIENCE FOUNDATION OF CHINA, grant number 82072795 .

Institutional Review Board Statement: Not applicable.

Informed Consent Statement: Not applicable.

Acknowledgments: We are grateful to Dr. Tadanori Tomita for his critical reading of this article and professional comments. We apologize to authors whose primary references could not be cited due to space limitations. Illustrations for Figures 2, 3 and 4 were created with www.biorender.com.

Conflicts of Interest: The authors declare no conflicts of interest.

\section{References}

1. Ostrom, Q.T.; Cioffi, G.; Gittleman, H.; Patil, N.; Waite, K.; Kruchko, C.; Barnholtz-Sloan, J.S. CBTRUS Statistical Report: Primary Brain and Other Central Nervous System Tumors Diagnosed in the United States in 2012-2016. Neuro Oncol 2019, 21, v1-v100, doi:10.1093/neuonc/noz150.

2. Cooney, T.; Lane, A.; Bartels, U.; Bouffet, E.; Goldman, S.; Leary, S.E.S.; Foreman, N.K.; Packer, R.J.; Broniscer, A.; Minturn, J.E., et al. Contemporary survival end points: an International Diffuse Intrinsic Pontine Glioma Registry study. Neuro Oncol 2017, 19, 1279-1280, doi:10.1093/neuonc/nox107.

3. Hargrave, D.; Bartels, U.; Bouffet, E. Diffuse brainstem glioma in children: critical review of clinical trials. Lancet Oncol 2006, 7, 241-248, doi:10.1016/s1470-2045(06)70615-5.

4. $\quad$ Khuong-Quang, D.A.; Buczkowicz, P.; Rakopoulos, P.; Liu, X.Y.; Fontebasso, A.M.; Bouffet, E.; Bartels, U.; Albrecht, S.; Schwartzentruber, J.; Letourneau, L., et al. K27M mutation in histone H3.3 defines clinically and biologically distinct subgroups of pediatric diffuse intrinsic pontine gliomas. Acta Neuropathol 2012, 124, 439-447, doi:10.1007/s00401-012-0998-0.

5. Wu, G.; Broniscer, A.; McEachron, T.A.; Lu, C.; Paugh, B.S.; Becksfort, J.; Qu, C.; Ding, L.; Huether, R.; Parker, M., et al. Somatic histone H3 alterations in pediatric diffuse intrinsic pontine gliomas and non-brainstem glioblastomas. Nat Genet 2012, 44, 251-253, doi:10.1038/ng.1102.

6. Schwartzentruber, J.; Korshunov, A.; Liu, X.Y.; Jones, D.T.; Pfaff, E.; Jacob, K.; Sturm, D.; Fontebasso, A.M.; Quang, D.A.; Tönjes, M., et al. Driver mutations in histone H3.3 and chromatin remodelling genes in paediatric glioblastoma. Nature 2012, 482, 226-231, doi:10.1038/nature10833.

7. Komori, T. The 2016 WHO Classification of Tumours of the Central Nervous System: The Major Points of Revision. Neurol Med Chir (Tokyo) 2017, 57, 301-311, doi:10.2176/nmc.ra.2017-0010.

8. Paugh, B.S.; Broniscer, A.; Qu, C.; Miller, C.P.; Zhang, J.; Tatevossian, R.G.; Olson, J.M.; Geyer, J.R.; Chi, S.N.; da Silva, N.S., et al. Genome-wide analyses identify recurrent amplifications of receptor tyrosine kinases and cell-cycle regulatory genes in diffuse intrinsic pontine glioma. $J$ Clin Oncol 2011, 29, 3999-4006, doi:10.1200/jco.2011.35.5677.

9. Park, J.; Lee, W.; Yun, S.; Kim, S.P.; Kim, K.H.; Kim, J.I.; Kim, S.K.; Wang, K.C.; Lee, J.Y. STAT3 is a key molecule in the oncogenic behavior of diffuse intrinsic pontine glioma. Oncol Lett 2020, 20, 
1989-1998, doi:10.3892/ol.2020.11699.

10. Wang, Z.; Xu, C.; Diplas, B.H.; Moure, C.J.; Chen, C.J.; Chen, L.H.; Du, C.; Zhu, H.; Greer, P.K.; Zhang, L., et al. Targeting Mutant PPM1D Sensitizes Diffuse Intrinsic Pontine Glioma Cells to the PARP Inhibitor Olaparib. Mol Cancer Res 2020, 18, 968-980, doi:10.1158/1541-7786.Mcr-190507.

11. Li, G.; Mitra, S.S.; Monje, M.; Henrich, K.N.; Bangs, C.D.; Nitta, R.T.; Wong, A.J. Expression of epidermal growth factor variant III (EGFRvIII) in pediatric diffuse intrinsic pontine gliomas. $J$ Neurooncol 2012, 108, 395-402, doi:10.1007/s11060-012-0842-3.

12. Solomon, D.A.; Wood, M.D.; Tihan, T.; Bollen, A.W.; Gupta, N.; Phillips, J.J.; Perry, A. Diffuse Midline Gliomas with Histone H3-K27M Mutation: A Series of 47 Cases Assessing the Spectrum of Morphologic Variation and Associated Genetic Alterations. Brain Pathol 2016, 26, 569-580, doi:10.1111/bpa.12336.

13. Mueller, S.; Hashizume, R.; Yang, X.; Kolkowitz, I.; Olow, A.K.; Phillips, J.; Smirnov, I.; Tom, M.W.; Prados, M.D.; James, C.D., et al. Targeting Wee1 for the treatment of pediatric high-grade gliomas. Neuro Oncol 2014, 16, 352-360, doi:10.1093/neuonc/not220.

14. Paugh, B.S.; Zhu, X.; Qu, C.; Endersby, R.; Diaz, A.K.; Zhang, J.; Bax, D.A.; Carvalho, D.; Reis, R.M.; Onar-Thomas, A., et al. Novel oncogenic PDGFRA mutations in pediatric high-grade gliomas. Cancer Res 2013, 73, 6219-6229, doi:10.1158/0008-5472.can-13-1491.

15. Fortin, J.; Tian, R.; Zarrabi, I.; Hill, G.; Williams, E.; Sanchez-Duffhues, G.; Thorikay, M.; Ramachandran, P.; Siddaway, R.; Wong, J.F., et al. Mutant ACVR1 Arrests Glial Cell Differentiation to Drive Tumorigenesis in Pediatric Gliomas. Cancer cell 2020, 37, 308-323.e312, doi:10.1016/j.ccell.2020.02.002.

16. Taylor, K.R.; Mackay, A.; Truffaux, N.; Butterfield, Y.; Morozova, O.; Philippe, C.; Castel, D.; Grasso, C.S.; Vinci, M.; Carvalho, D., et al. Recurrent activating ACVR1 mutations in diffuse intrinsic pontine glioma. Nat Genet 2014, 46, 457-461, doi:10.1038/ng.2925.

17. Hoeman, C.M.; Cordero, F.J.; Hu, G.; Misuraca, K.; Romero, M.M.; Cardona, H.J.; Nazarian, J.; Hashizume, R.; McLendon, R.; Yu, P., et al. ACVR1 R206H cooperates with H3.1K27M in promoting diffuse intrinsic pontine glioma pathogenesis. Nat Commun 2019, 10, 1023, doi:10.1038/s41467-019-08823-9.

18. Cao, H.; Jin, M.; Gao, M.; Zhou, H.; Tao, Y.J.; Skolnick, J. Differential kinase activity of ACVR1 G328V and R206H mutations with implications to possible T $\beta$ RI cross-talk in diffuse intrinsic pontine glioma. Sci Rep 2020, 10, 6140, doi:10.1038/s41598-020-63061-0.

19. Taylor, I.C.; Hütt-Cabezas, M.; Brandt, W.D.; Kambhampati, M.; Nazarian, J.; Chang, H.T.; Warren, K.E.; Eberhart, C.G.; Raabe, E.H. Disrupting NOTCH Slows Diffuse Intrinsic Pontine Glioma Growth, Enhances Radiation Sensitivity, and Shows Combinatorial Efficacy With Bromodomain Inhibition. J Neuropathol Exp Neurol 2015, 74, 778-790, doi:10.1097/nen.0000000000000216.

20. Chung, C.; Sweha, S.R.; Pratt, D.; Tamrazi, B.; Panwalkar, P.; Banda, A.; Bayliss, J.; Hawes, D.; Yang, F.; Lee, H.J., et al. Integrated Metabolic and Epigenomic Reprograming by H3K27M Mutations in Diffuse Intrinsic Pontine Gliomas. Cancer cell 2020, 38, 334-349.e339, doi:10.1016/j.ccell.2020.07.008.

21. Lee, S.; Kambhampati, M.; Yadavilli, S.; Gordish-Dressman, H.; Santi, M.; Cruz, C.R.; Packer, R.J.; Almira-Suarez, M.I.; Hwang, E.I.; Nazarian, J. Differential Expression of Wilms' Tumor Protein in Diffuse Intrinsic Pontine Glioma. J Neuropathol Exp Neurol 2019, 78, 380-388, 
doi:10.1093/jnen/nlz021.

22. Caretti, V.; Hiddingh, L.; Lagerweij, T.; Schellen, P.; Koken, P.W.; Hulleman, E.; van Vuurden, D.G.; Vandertop, W.P.; Kaspers, G.J.; Noske, D.P., et al. WEE1 kinase inhibition enhances the radiation response of diffuse intrinsic pontine gliomas. Mol Cancer Ther 2013, 12, 141-150, doi:10.1158/1535-7163.Mct-12-0735.

23. Zanazzi, G.; Liechty, B.L.; Pendrick, D.; Krasnozhen-Ratush, O.; Snuderl, M.; Allen, J.C.; Garvin, J.H.; Mansukhani, M.M.; Roth, K.A.; Hsiao, S.J. Diffuse midline glioma with novel, potentially targetable, FGFR2-VPS35 fusion. Cold Spring Harb Mol Case Stud 2020, 6, doi:10.1101/mcs.a005660.

24. Tomita, T.; McLone, D.G.; Naidich, T.P. Brain stem gliomas in childhood. Rational approach and treatment. J Neurooncol 1984, 2, 117-122, doi:10.1007/bf00177896.

25. Xi, G.; Rajaram, V.; Mania-Farnell, B.; Mayanil, C.S.; Soares, M.B.; Tomita, T.; Goldman, S. Efficacy of vincristine administered via convection-enhanced delivery in a rodent brainstem tumor model documented by bioluminescence imaging. Childs Nerv Syst 2012, 28, 565-574, doi:10.1007/s00381-012-1690-3.

26. Roujeau, T.; Machado, G.; Garnett, M.R.; Miquel, C.; Puget, S.; Geoerger, B.; Grill, J.; Boddaert, N.; Di Rocco, F.; Zerah, M., et al. Stereotactic biopsy of diffuse pontine lesions in children. J Neurosurg 2007, 107, 1-4, doi:10.3171/ped-07/07/001.

27. Hashizume, R.; Gupta, N. Patient-derived Tumor Models for Diffuse Intrinsic Pontine Gliomas. Curr Neuropharmacol 2017, 15, 98-103, doi:10.2174/1570159x14666160523144117.

28. Caretti, V.; Zondervan, I.; Meijer, D.H.; Idema, S.; Vos, W.; Hamans, B.; Bugiani, M.; Hulleman, E.; Wesseling, P.; Vandertop, W.P., et al. Monitoring of tumor growth and post-irradiation recurrence in a diffuse intrinsic pontine glioma mouse model. Brain Pathol 2011, 21, 441-451, doi:10.1111/j.1750-3639.2010.00468.x.

29. Misuraca, K.L.; Cordero, F.J.; Becher, O.J. Pre-Clinical Models of Diffuse Intrinsic Pontine Glioma. Front Oncol 2015, 5, 172, doi:10.3389/fonc.2015.00172.

30. Lieberman, N.A.P.; DeGolier, K.; Kovar, H.M.; Davis, A.; Hoglund, V.; Stevens, J.; Winter, C.; Deutsch, G.; Furlan, S.N.; Vitanza, N.A., et al. Characterization of the immune microenvironment of diffuse intrinsic pontine glioma: implications for development of immunotherapy. Neuro Oncol 2019, 21, 83-94, doi:10.1093/neuonc/noy145.

31. Harris, W. A Case of Pontine Glioma, with Special Reference to the Paths of Gustatory Sensation. Proc R Soc Med 1926, 19, 1-5.

32. Pincus, D.W.; Richter, E.O.; Yachnis, A.T.; Bennett, J.; Bhatti, M.T.; Smith, A. Brainstem stereotactic biopsy sampling in children. J Neurosurg 2006, 104, 108-114, doi:10.3171/ped.2006.104.2.108.

33. Broniscer, A.; Baker, J.N.; Baker, S.J.; Chi, S.N.; Geyer, J.R.; Morris, E.B.; Gajjar, A. Prospective collection of tissue samples at autopsy in children with diffuse intrinsic pontine glioma. Cancer 2010, 116, 4632-4637, doi:10.1002/cncr.25405.

34. Zarghooni, M.; Bartels, U.; Lee, E.; Buczkowicz, P.; Morrison, A.; Huang, A.; Bouffet, E.; Hawkins, C. Whole-genome profiling of pediatric diffuse intrinsic pontine gliomas highlights plateletderived growth factor receptor alpha and poly (ADP-ribose) polymerase as potential therapeutic targets. J Clin Oncol 2010, 28, 1337-1344, doi:10.1200/jco.2009.25.5463.

35. Sturm, D.; Witt, H.; Hovestadt, V.; Khuong-Quang, D.A.; Jones, D.T.; Konermann, C.; Pfaff, E.; Tönjes, M.; Sill, M.; Bender, S., et al. Hotspot mutations in H3F3A and IDH1 define distinct epigenetic and biological subgroups of glioblastoma. Cancer cell 2012, 22, 425-437, 
doi:10.1016/j.ccr.2012.08.024.

36. Nikbakht, H.; Panditharatna, E.; Mikael, L.G.; Li, R.; Gayden, T.; Osmond, M.; Ho, C.Y.; Kambhampati, M.; Hwang, E.I.; Faury, D., et al. Spatial and temporal homogeneity of driver mutations in diffuse intrinsic pontine glioma. Nat Commun 2016, 7, 11185, doi:10.1038/ncomms11185.

37. Lewis, P.W.; Müller, M.M.; Koletsky, M.S.; Cordero, F.; Lin, S.; Banaszynski, L.A.; Garcia, B.A.; Muir, T.W.; Becher, O.J.; Allis, C.D. Inhibition of PRC2 activity by a gain-of-function H3 mutation found in pediatric glioblastoma. Science (New York, N.Y.) 2013, 340, 857-861, doi:10.1126/science.1232245.

38. Mondal, G.; Lee, J.C.; Ravindranathan, A.; Villanueva-Meyer, J.E.; Tran, Q.T.; Allen, S.J.; Barreto, J.; Gupta, R.; Doo, P.; Van Ziffle, J., et al. Pediatric bithalamic gliomas have a distinct epigenetic signature and frequent EGFR exon 20 insertions resulting in potential sensitivity to targeted kinase inhibition. Acta Neuropathol 2020, 139, 1071-1088, doi:10.1007/s00401-020-02155-5.

39. Castel, D.; Philippe, C.; Calmon, R.; Le Dret, L.; Truffaux, N.; Boddaert, N.; Pagès, M.; Taylor, K.R.; Saulnier, P.; Lacroix, L., et al. Histone H3F3A and HIST1H3B K27M mutations define two subgroups of diffuse intrinsic pontine gliomas with different prognosis and phenotypes. Acta Neuropathol 2015, 130, 815-827, doi:10.1007/s00401-015-1478-0.

40. Harutyunyan, A.S.; Krug, B.; Chen, H.; Papillon-Cavanagh, S.; Zeinieh, M.; De Jay, N.; Deshmukh, S.; Chen, C.C.L.; Belle, J.; Mikael, L.G., et al. H3K27M induces defective chromatin spread of PRC2-mediated repressive H3K27me2/me3 and is essential for glioma tumorigenesis. Nat Commun 2019, 10, 1262, doi:10.1038/s41467-019-09140-x.

41. Chan, K.M.; Fang, D.; Gan, H.; Hashizume, R.; Yu, C.; Schroeder, M.; Gupta, N.; Mueller, S.; James, C.D.; Jenkins, R., et al. The histone H3.3K27M mutation in pediatric glioma reprograms H3K27 methylation and gene expression. Genes Dev 2013, 27, 985-990, doi:10.1101/gad.217778.113.

42. Bender, S.; Tang, Y.; Lindroth, A.M.; Hovestadt, V.; Jones, D.T.; Kool, M.; Zapatka, M.; Northcott, P.A.; Sturm, D.; Wang, W., et al. Reduced H3K27me3 and DNA hypomethylation are major drivers of gene expression in K27M mutant pediatric high-grade gliomas. Cancer cell 2013, 24, 660-672, doi:10.1016/j.ccr.2013.10.006.

43. Bechet, D.; Gielen, G.G.; Korshunov, A.; Pfister, S.M.; Rousso, C.; Faury, D.; Fiset, P.O.; Benlimane, N.; Lewis, P.W.; Lu, C., et al. Specific detection of methionine 27 mutation in histone 3 variants $(\mathrm{H} 3 \mathrm{~K} 27 \mathrm{M})$ in fixed tissue from high-grade astrocytomas. Acta Neuropathol 2014, 128, 733-741, doi:10.1007/s00401-014-1337-4.

44. Piunti, A.; Hashizume, R.; Morgan, M.A.; Bartom, E.T.; Horbinski, C.M.; Marshall, S.A.; Rendleman, E.J.; Ma, Q.; Takahashi, Y.H.; Woodfin, A.R., et al. Therapeutic targeting of polycomb and BET bromodomain proteins in diffuse intrinsic pontine gliomas. Nat Med 2017, 23, 493-500, doi:10.1038/nm.4296.

45. Justin, N.; Zhang, Y.; Tarricone, C.; Martin, S.R.; Chen, S.; Underwood, E.; De Marco, V.; Haire, L.F.; Walker, P.A.; Reinberg, D., et al. Structural basis of oncogenic histone H3K27M inhibition of human polycomb repressive complex 2. Nat Commun 2016, 7, 11316, doi:10.1038/ncomms11316.

46. Castel, D.; Philippe, C.; Kergrohen, T.; Sill, M.; Merlevede, J.; Barret, E.; Puget, S.; Sainte-Rose, C.; Kramm, C.M.; Jones, C., et al. Transcriptomic and epigenetic profiling of 'diffuse midline gliomas, H3 K27M-mutant' discriminate two subgroups based on the type of histone H3 mutated and not 
supratentorial or infratentorial location. Acta Neuropathol Commun 2018, 6, 117, doi:10.1186/s40478-018-0614-1.

47. Nagaraja, S.; Vitanza, N.A.; Woo, P.J.; Taylor, K.R.; Liu, F.; Zhang, L.; Li, M.; Meng, W.; Ponnuswami, A.; Sun, W., et al. Transcriptional Dependencies in Diffuse Intrinsic Pontine Glioma. Cancer Cell 2017, 31, 635-652 e636, doi:10.1016/j.ccell.2017.03.011.

48. Nagaraja, S.; Quezada, M.A.; Gillespie, S.M.; Arzt, M.; Lennon, J.J.; Woo, P.J.; Hovestadt, V.; Kambhampati, M.; Filbin, M.G.; Suva, M.L., et al. Histone Variant and Cell Context Determine H3K27M Reprogramming of the Enhancer Landscape and Oncogenic State. Mol Cell 2019, 76, 965-980.e912, doi:10.1016/j.molcel.2019.08.030.

49. Bailey, C.P.; Figueroa, M.; Gangadharan, A.; Yang, Y.; Romero, M.M.; Kennis, B.A.; Yadavilli, S.; Henry, V.; Collier, T.; Monje, M., et al. Pharmacologic inhibition of lysine specific demethylase1 (LSD1) as a therapeutic and immune-sensitization strategy in pediatric high grade glioma (pHGG). Neuro Oncol 2020, 22, 1302-1314, doi:10.1093/neuonc/noaa058.

50. Chan, K.M.; Han, J.; Fang, D.; Gan, H.; Zhang, Z. A lesson learned from the H3.3K27M mutation found in pediatric glioma: a new approach to the study of the function of histone modifications in vivo? Cell Cycle 2013, 12, 2546-2552, doi:10.4161/cc.25625.

51. Ahsan, S.; Raabe, E.H.; Haffner, M.C.; Vaghasia, A.; Warren, K.E.; Quezado, M.; Ballester, L.Y.; Nazarian, J.; Eberhart, C.G.; Rodriguez, F.J. Increased 5-hydroxymethylcytosine and decreased 5 -methylcytosine are indicators of global epigenetic dysregulation in diffuse intrinsic pontine glioma. Acta Neuropathol Commun 2014, 2, 59, doi:10.1186/2051-5960-2-59.

52. Gu, B.; Lee, M.G. Histone H3 lysine 4 methyltransferases and demethylases in self-renewal and differentiation of stem cells. Cell Biosci 2013, 3, 39, doi:10.1186/2045-3701-3-39.

53. An, S.; Camarillo, J.M.; Huang, T.Y.; Li, D.; Morris, J.A.; Zoltek, M.A.; Qi, J.; Behbahani, M.; Kambhampati, M.; Kelleher, N.L., et al. Histone tail analysis reveals H3K36me2 and H4K16ac as epigenetic signatures of diffuse intrinsic pontine glioma. J Exp Clin Cancer Res 2020, 39, 261, doi:10.1186/s13046-020-01773-x.

54. Pedersen, H.; Schmiegelow, K.; Hamerlik, P. Radio-Resistance and DNA Repair in Pediatric Diffuse Midline Gliomas. Cancers 2020, 12, doi:10.3390/cancers12102813.

55. Miyahara, H.; Yadavilli, S.; Natsumeda, M.; Rubens, J.A.; Rodgers, L.; Kambhampati, M.; Taylor, I.C.; Kaur, H.; Asnaghi, L.; Eberhart, C.G., et al. The dual mTOR kinase inhibitor TAK228 inhibits tumorigenicity and enhances radiosensitization in diffuse intrinsic pontine glioma. Cancer Lett 2017, 400, 110-116, doi:10.1016/j.canlet.2017.04.019.

56. Wu, G.; Diaz, A.K.; Paugh, B.S.; Rankin, S.L.; Ju, B.; Li, Y.; Zhu, X.; Qu, C.; Chen, X.; Zhang, J., et al. The genomic landscape of diffuse intrinsic pontine glioma and pediatric non-brainstem highgrade glioma. Nat Genet 2014, 46, 444-450, doi:10.1038/ng.2938.

57. Mackay, A.; Burford, A.; Carvalho, D.; Izquierdo, E.; Fazal-Salom, J.; Taylor, K.R.; Bjerke, L.; Clarke, M.; Vinci, M.; Nandhabalan, M., et al. Integrated Molecular Meta-Analysis of 1,000 Pediatric High-Grade and Diffuse Intrinsic Pontine Glioma. Cancer cell 2017, 32, 520-537.e525, doi:10.1016/j.ccell.2017.08.017.

58. Vinci, M.; Burford, A.; Molinari, V.; Kessler, K.; Popov, S.; Clarke, M.; Taylor, K.R.; Pemberton, H.N.; Lord, C.J.; Gutteridge, A., et al. Functional diversity and cooperativity between subclonal populations of pediatric glioblastoma and diffuse intrinsic pontine glioma cells. Nat Med 2018, 24, 1204-1215, doi:10.1038/s41591-018-0086-7.

59. Eden, C.J.; Ju, B.; Murugesan, M.; Phoenix, T.N.; Nimmervoll, B.; Tong, Y.; Ellison, D.W.; 
Finkelstein, D.; Wright, K.; Boulos, N., et al. Orthotopic models of pediatric brain tumors in zebrafish. Oncogene 2015, 34, 1736-1742, doi:10.1038/onc.2014.107.

60. Sho, A.; Kondo, S.; Kamitani, H.; Otake, M.; Watanabe, T. Establishment of experimental glioma models at the intrinsic brainstem region of the rats. Neurol Res 2007, 29, 36-42, doi:10.1179/016164106x115080.

61. Barth, R.F. ; Kaur, B. Rat brain tumor models in experimental neuro-oncology: the 9L, C6, T9, F98, RG2 (D74), RT-2 and CNS-1 gliomas. J Neurooncol 2009, 94, 299-312, doi:10.1007/s11060-0099875-7.

62. Wu, Q.; Tyler, B.; Sukay, L.; Rhines, L.; DiMeco, F.; Clatterbuck, R.E.; Guarnieri, M.; Carson, B.S., Sr. Experimental rodent models of brainstem tumors. Vet Pathol 2002, 39, 293-299, doi:10.1354/vp.39-3-293.

63. Hashizume, R.; Ozawa, T.; Dinca, E.B.; Banerjee, A.; Prados, M.D.; James, C.D.; Gupta, N. A human brainstem glioma xenograft model enabled for bioluminescence imaging. J Neurooncol 2010, 96, 151-159, doi:10.1007/s11060-009-9954-9.

64. Aoki, Y.; Hashizume, R.; Ozawa, T.; Banerjee, A.; Prados, M.; James, C.D.; Gupta, N. An experimental xenograft mouse model of diffuse pontine glioma designed for therapeutic testing. J Neurooncol 2012, 108, 29-35, doi:10.1007/s11060-011-0796-x.

65. Klopp, L.S.; Simpson, S.T.; Sorjonen, D.A.; Lenz, S.D. Ventral surgical approach to the caudal brain stem in dogs. Vet Surg 2000, 29, 533-542, doi:10.1053/jvet.2000.17851.

66. Walsh, J.W.; Zimmer, S.G.; Oeltgen, J.; Markesbery, W.R. Invasiveness in primary intracranial tumors: Part 1. An experimental model using cloned SV40 virus-produced hamster brain tumors. Neurosurgery 1986, 19, 185-200, doi:10.1227/00006123-198608000-00003.

67. Tabuchi, K.; Nishimoto, A.; Matsumoto, K.; Satoh, T.; Nakasone, S.; Fujiwara, T.; Ogura, H. Establishment of a brain-tumor model in adult monkeys. J Neurosurg 1985, 63, 912-916, doi:10.3171/jns.1985.63.6.0912.

68. Lonser, R.R.; Walbridge, S.; Vortmeyer, A.O.; Pack, S.D.; Nguyen, T.T.; Gogate, N.; Olson, J.J.; Akbasak, A.; Bobo, R.H.; Goffman, T., et al. Induction of glioblastoma multiforme in nonhuman primates after therapeutic doses of fractionated whole-brain radiation therapy. J Neurosurg 2002, 97, 1378-1389, doi:10.3171/jns.2002.97.6.1378.

69. Jallo, G.I.; Penno, M.; Sukay, L.; Liu, J.Y.; Tyler, B.; Lee, J.; Carson, B.S.; Guarnieri, M. Experimental models of brainstem tumors: development of a neonatal rat model. Childs Nerv Syst 2005, 21, 399-403, doi:10.1007/s00381-004-1100-6.

70. Lee, J.; Jallo, G.I.; Guarnieri, M.; Carson, B.S., Sr.; Penno, M.B. A novel brainstem tumor model: guide screw technology with functional, radiological, and histopathological characterization. Neurosurg Focus 2005, 18, E11.

71. Kondo, A.; Goldman, S.; Vanin, E.F.; Sredni, S.T.; Rajaram, V.; Soares, M.B.; Tomita, T. An experimental brainstem tumor model using in vivo bioluminescence imaging in rat. Childs Nero Syst 2009, 25, 527-533, doi:10.1007/s00381-008-0783-5.

72. Schuelke, M.R.; Wongthida, P.; Thompson, J.; Kottke, T.; Driscoll, C.B.; Huff, A.L.; Shim, K.G.; Coffey, M.; Pulido, J.; Evgin, L., et al. Diverse immunotherapies can effectively treat syngeneic brainstem tumors in the absence of overt toxicity. J Immunother Cancer 2019, 7, 188, doi:10.1186/s40425-019-0673-2.

73. Hashizume, R.; Smirnov, I.; Liu, S.; Phillips, J.J.; Hyer, J.; McKnight, T.R.; Wendland, M.; Prados, M.; Banerjee, A.; Nicolaides, T., et al. Characterization of a diffuse intrinsic pontine glioma cell 
line: implications for future investigations and treatment. J Neurooncol 2012, 110, 305-313, doi:10.1007/s11060-012-0973-6.

74. Huillard, E.; Hashizume, R.; Phillips, J.J.; Griveau, A.; Ihrie, R.A.; Aoki, Y.; Nicolaides, T.; Perry, A.; Waldman, T.; McMahon, M., et al. Cooperative interactions of BRAFV600E kinase and CDKN2A locus deficiency in pediatric malignant astrocytoma as a basis for rational therapy. Proc Natl Acad Sci U S A 2012, 109, 8710-8715, doi:10.1073/pnas.1117255109.

75. Bailey, S.; Howman, A.; Wheatley, K.; Wherton, D.; Boota, N.; Pizer, B.; Fisher, D.; Kearns, P.; Picton, S.; Saran, F., et al. Diffuse intrinsic pontine glioma treated with prolonged temozolomide and radiotherapy--results of a United Kingdom phase II trial (CNS 2007 04). Eur J Cancer 2013, 49, 3856-3862, doi:10.1016/j.ejca.2013.08.006.

76. DeWire, M.; Fuller, C.; Hummel, T.R.; Chow, L.M.L.; Salloum, R.; de Blank, P.; Pater, L.; Lawson, S.; Zhu, X.; Dexheimer, P., et al. A phase I/II study of ribociclib following radiation therapy in children with newly diagnosed diffuse intrinsic pontine glioma (DIPG). J Neurooncol 2020, doi:10.1007/s11060-020-03641-2.

77. Monje, M.; Mitra, S.S.; Freret, M.E.; Raveh, T.B.; Kim, J.; Masek, M.; Attema, J.L.; Li, G.; Haddix, T.; Edwards, M.S., et al. Hedgehog-responsive candidate cell of origin for diffuse intrinsic pontine glioma. Proc Natl Acad Sci U S A 2011, 108, 4453-4458, doi:10.1073/pnas.1101657108.

78. $\quad$ Lin, G.L.; Wilson, K.M.; Ceribelli, M.; Stanton, B.Z.; Woo, P.J.; Kreimer, S.; Qin, E.Y.; Zhang, X.; Lennon, J.; Nagaraja, S., et al. Therapeutic strategies for diffuse midline glioma from highthroughput combination drug screening. Sci Transl Med 2019, 11, doi:10.1126/scitranslmed.aaw0064.

79. Meel, M.H.; de Gooijer, M.C.; Guillén Navarro, M.; Waranecki, P.; Breur, M.; Buil, L.C.M.; Wedekind, L.E.; Twisk, J.W.R.; Koster, J.; Hashizume, R., et al. MELK Inhibition in Diffuse Intrinsic Pontine Glioma. Clin Cancer Res 2018, 24, 5645-5657, doi:10.1158/1078-0432.ccr-18-0924.

80. Chornenkyy, Y.; Agnihotri, S.; Yu, M.; Buczkowicz, P.; Rakopoulos, P.; Golbourn, B.; Garzia, L.; Siddaway, R.; Leung, S.; Rutka, J.T., et al. Poly-ADP-Ribose Polymerase as a Therapeutic Target in Pediatric Diffuse Intrinsic Pontine Glioma and Pediatric High-Grade Astrocytoma. Mol Cancer Ther 2015, 14, 2560-2568, doi:10.1158/1535-7163.mct-15-0282.

81. Fons, N.R.; Sundaram, R.K.; Breuer, G.A.; Peng, S.; McLean, R.L.; Kalathil, A.N.; Schmidt, M.S.; Carvalho, D.M.; Mackay, A.; Jones, C., et al. PPM1D mutations silence NAPRT gene expression and confer NAMPT inhibitor sensitivity in glioma. Nat Commun 2019, 10, 3790, doi:10.1038/s41467-019-11732-6.

82. Carvalho, D.; Taylor, K.R.; Olaciregui, N.G.; Molinari, V.; Clarke, M.; Mackay, A.; Ruddle, R.; Henley, A.; Valenti, M.; Hayes, A., et al. ALK2 inhibitors display beneficial effects in preclinical models of ACVR1 mutant diffuse intrinsic pontine glioma. Commun Biol 2019, 2, 156, doi:10.1038/s42003-019-0420-8.

83. Anastas, J.N.; Zee, B.M.; Kalin, J.H.; Kim, M.; Guo, R.; Alexandrescu, S.; Blanco, M.A.; Giera, S.; Gillespie, S.M.; Das, J., et al. Re-programing Chromatin with a Bifunctional LSD1/HDAC Inhibitor Induces Therapeutic Differentiation in DIPG. Cancer cell 2019, 36, 528-544.e510, doi:10.1016/j.ccell.2019.09.005.

84. Grasso, C.S.; Tang, Y.; Truffaux, N.; Berlow, N.E.; Liu, L.; Debily, M.A.; Quist, M.J.; Davis, L.E.; Huang, E.C.; Woo, P.J., et al. Functionally defined therapeutic targets in diffuse intrinsic pontine glioma. Nat Med 2015, 21, 827, doi:10.1038/nm0715-827a.

85. Kumar, S.S.; Sengupta, S.; Lee, K.; Hura, N.; Fuller, C.; DeWire, M.; Stevenson, C.B.; Fouladi, M.; 
Drissi, R. BMI-1 is a potential therapeutic target in diffuse intrinsic pontine glioma. Oncotarget 2017, 8, 62962-62975, doi:10.18632/oncotarget.18002.

Martínez-Vélez, N.; Garcia-Moure, M.; Marigil, M.; González-Huarriz, M.; Puigdelloses, M.; Gallego Pérez-Larraya, J.; Zalacaín, M.; Marrodán, L.; Varela-Guruceaga, M.; Laspidea, V., et al. The oncolytic virus Delta-24-RGD elicits an antitumor effect in pediatric glioma and DIPG mouse models. Nat Commun 2019, 10, 2235, doi:10.1038/s41467-019-10043-0.

87. Abe, H.; Natsumeda, M.; Okada, M.; Watanabe, J.; Tsukamoto, Y.; Kanemaru, Y.; Yoshimura, J.; Oishi, M.; Hashizume, R.; Kakita, A., et al. MGMT Expression Contributes to Temozolomide Resistance in H3K27M-Mutant Diffuse Midline Gliomas. Front Oncol 2020, 9, 1568, doi:10.3389/fonc.2019.01568.

88. Silveira, A.B.; Kasper, L.H.; Fan, Y.; Jin, H.; Wu, G.; Shaw, T.I.; Zhu, X.; Larson, J.D.; Easton, J.; Shao, Y., et al. H3.3 K27M depletion increases differentiation and extends latency of diffuse intrinsic pontine glioma growth in vivo. Acta Neuropathol 2019, 137, 637-655, doi:10.1007/s00401019-01975-4.

89. Sengupta, S.; Sobo, M.; Lee, K.; Senthil Kumar, S.; White, A.R.; Mender, I.; Fuller, C.; Chow, L.M.L.; Fouladi, M.; Shay, J.W., et al. Induced Telomere Damage to Treat Telomerase Expressing Therapy-Resistant Pediatric Brain Tumors. Mol Cancer Ther 2018, 17, 1504-1514, doi:10.1158/15357163.mct-17-0792.

90. Meel, M.H.; de Gooijer, M.C.; Metselaar, D.S.; Sewing, A.C.P.; Zwaan, K.; Waranecki, P.; Breur, M.; Buil, L.C.M.; Lagerweij, T.; Wedekind, L.E., et al. Combined Therapy of AXL and HDAC Inhibition Reverses Mesenchymal Transition in Diffuse Intrinsic Pontine Glioma. Clin Cancer Res 2020, 26, 3319-3332, doi:10.1158/1078-0432.ccr-19-3538.

91. Mohammad, F.; Weissmann, S.; Leblanc, B.; Pandey, D.P.; Højfeldt, J.W.; Comet, I.; Zheng, C.; Johansen, J.V.; Rapin, N.; Porse, B.T., et al. EZH2 is a potential therapeutic target for H3K27Mmutant pediatric gliomas. Nat Med 2017, 23, 483-492, doi:10.1038/nm.4293.

92. Pal, S.; Kozono, D.; Yang, X.; Fendler, W.; Fitts, W.; Ni, J.; Alberta, J.A.; Zhao, J.; Liu, K.X.; Bian, J., et al. Dual HDAC and PI3K Inhibition Abrogates NFאB- and FOXM1-Mediated DNA Damage Response to Radiosensitize Pediatric High-Grade Gliomas. Cancer Res 2018, 78, 4007-4021, doi:10.1158/0008-5472.can-17-3691.

93. Hashizume, R.; Andor, N.; Ihara, Y.; Lerner, R.; Gan, H.; Chen, X.; Fang, D.; Huang, X.; Tom, M.W.; Ngo, V., et al. Pharmacologic inhibition of histone demethylation as a therapy for pediatric brainstem glioma. Nat Med 2014, 20, 1394-1396, doi:10.1038/nm.3716.

94. Hennika, T.; Hu, G.; Olaciregui, N.G.; Barton, K.L.; Ehteda, A.; Chitranjan, A.; Chang, C.; Gifford, A.J.; Tsoli, M.; Ziegler, D.S., et al. Pre-Clinical Study of Panobinostat in Xenograft and Genetically Engineered Murine Diffuse Intrinsic Pontine Glioma Models. PloS one 2017, 12, e0169485, doi:10.1371/journal.pone.0169485.

95. Jansen, M.H.; Lagerweij, T.; Sewing, A.C.; Vugts, D.J.; van Vuurden, D.G.; Molthoff, C.F.; Caretti, V.; Veringa, S.J.; Petersen, N.; Carcaboso, A.M., et al. Bevacizumab Targeting Diffuse Intrinsic Pontine Glioma: Results of 89Zr-Bevacizumab PET Imaging in Brain Tumor Models. Mol Cancer Ther 2016, 15, 2166-2174, doi:10.1158/1535-7163.mct-15-0558.

96. Hersh, D.S.; Kumar, R.; Moore, K.A.; Smith, L.G.F.; Tinkle, C.L.; Chiang, J.; Patay, Z.; Gajjar, A.; Choudhri, A.F.; Lee-Diaz, J.A., et al. Safety and efficacy of brainstem biopsy in children and young adults. J Neurosurg Pediatr 2020, 10.3171/2020.4.Peds2092, 1-11, doi:10.3171/2020.4.Peds2092. 
97. Williams, J.R.; Young, C.C.; Vitanza, N.A.; McGrath, M.; Feroze, A.H.; Browd, S.R.; Hauptman, J.S. Progress in diffuse intrinsic pontine glioma: advocating for stereotactic biopsy in the standard of care. Neurosurg Focus 2020, 48, E4, doi:10.3171/2019.9.FOCUS19745.

98. Lindquist, R.A.; Guinto, C.D.; Rodas-Rodriguez, J.L.; Fuentealba, L.C.; Tate, M.C.; Rowitch, D.H.; Alvarez-Buylla, A. Identification of proliferative progenitors associated with prominent postnatal growth of the pons. Nat Commun 2016, 7, 11628, doi:10.1038/ncomms11628.

99. Misuraca, K.L.; Hu, G.; Barton, K.L.; Chung, A.; Becher, O.J. A Novel Mouse Model of Diffuse Intrinsic Pontine Glioma Initiated in Pax3-Expressing Cells. Neoplasia (New York, N.Y.) 2016, 18, 60-70, doi:10.1016/j.neo.2015.12.002.

100. Barton, K.L.; Misuraca, K.; Cordero, F.; Dobrikova, E.; Min, H.D.; Gromeier, M.; Kirsch, D.G.; Becher, O.J. PD-0332991, a CDK4/6 inhibitor, significantly prolongs survival in a genetically engineered mouse model of brainstem glioma. Plos one 2013, 8, e77639, doi:10.1371/journal.pone.0077639.

101. Becher, O.J.; Hambardzumyan, D.; Walker, T.R.; Helmy, K.; Nazarian, J.; Albrecht, S.; Hiner, R.L.; Gall, S.; Huse, J.T.; Jabado, N., et al. Preclinical evaluation of radiation and perifosine in a genetically and histologically accurate model of brainstem glioma. Cancer Res 2010, 70, 2548-2557, doi:10.1158/0008-5472.can-09-2503.

102. Funato, K.; Major, T.; Lewis, P.W.; Allis, C.D.; Tabar, V. Use of human embryonic stem cells to model pediatric gliomas with H3.3K27M histone mutation. Science (New York, N.Y.) 2014, 346, 1529-1533, doi:10.1126/science.1253799.

103. Pathania, M.; De Jay, N.; Maestro, N.; Harutyunyan, A.S.; Nitarska, J.; Pahlavan, P.; Henderson, S.; Mikael, L.G.; Richard-Londt, A.; Zhang, Y., et al. H3.3(K27M) Cooperates with Trp53 Loss and PDGFRA Gain in Mouse Embryonic Neural Progenitor Cells to Induce Invasive High-Grade Gliomas. Cancer cell 2017, 32, 684-700.e689, doi:10.1016/j.ccell.2017.09.014.

104. Larson, J.D.; Kasper, L.H.; Paugh, B.S.; Jin, H.; Wu, G.; Kwon, C.H.; Fan, Y.; Shaw, T.I.; Silveira, A.B.; Qu, C., et al. Histone H3.3 K27M Accelerates Spontaneous Brainstem Glioma and Drives Restricted Changes in Bivalent Gene Expression. Cancer cell 2019, 35, 140-155.e147, doi:10.1016/j.ccell.2018.11.015.

105. Halvorson, K.G.; Barton, K.L.; Schroeder, K.; Misuraca, K.L.; Hoeman, C.; Chung, A.; Crabtree, D.M.; Cordero, F.J.; Singh, R.; Spasojevic, I., et al. A high-throughput in vitro drug screen in a genetically engineered mouse model of diffuse intrinsic pontine glioma identifies BMS-754807 as a promising therapeutic agent. PLoS One 2015, 10, e0118926, doi:10.1371/journal.pone.0118926.

106. Grabovska, Y.; Mackay, A.; O'Hare, P.; Crosier, S.; Finetti, M.; Schwalbe, E.C.; Pickles, J.C.; Fairchild, A.R.; Avery, A.; Cockle, J., et al. Pediatric pan-central nervous system tumor analysis of immune-cell infiltration identifies correlates of antitumor immunity. Nat Commun 2020, 11, 4324, doi:10.1038/s41467-020-18070-y.

107. Aliica Lenzen, K.L.L., Lijie Zhai, Erik Ladomersky, Pichia Raman, Komal Rathi, Rishi R. Lulla, Rintaro Hashizume, Derek A. Wainwright. Novel RNA-targeting strategy for treating T celldriven immunosuppression in human diffuse intrinsic pontine glioma. Neuro Oncol 2019 Suppl 2, ii92-ii93, doi:10.1093/neuonc/noz036.122.

108. Mount, C.W.; Majzner, R.G.; Sundaresh, S.; Arnold, E.P.; Kadapakkam, M.; Haile, S.; Labanieh, L.; Hulleman, E.; Woo, P.J.; Rietberg, S.P., et al. Potent antitumor efficacy of anti-GD2 CAR T cells in H3-K27M(+) diffuse midline gliomas. Nat Med 2018, 24, 572-579, doi:10.1038/s41591-0180006-x. 
109. Gholamin, S.; Mitra, S.S.; Feroze, A.H.; Liu, J.; Kahn, S.A.; Zhang, M.; Esparza, R.; Richard, C.; Ramaswamy, V.; Remke, M., et al. Disrupting the CD47-SIRP $\alpha$ anti-phagocytic axis by a humanized anti-CD47 antibody is an efficacious treatment for malignant pediatric brain tumors. Sci Transl Med 2017, 9, doi:10.1126/scitranslmed.aaf2968.

110. Shultz, L.D.; Ishikawa, F.; Greiner, D.L. Humanized mice in translational biomedical research. Nat Rev Immunol 2007, 7, 118-130, doi:10.1038/nri2017.

111. Ito, R.; Takahashi, T.; Katano, I.; Ito, M. Current advances in humanized mouse models. Cell Mol Immunol 2012, 9, 208-214, doi:10.1038/cmi.2012.2.

112. Baiocchi, R.A.; Khatri, V.P.; Lindemann, M.J.; Ross, M.E.; Papoff, G.; Caprio, A.J.; Caprio, T.V.; Fenstermaker, R.; Ruberti, G.; Bernstein, Z.P., et al. Phenotypic and functional analysis of Fas (CD95) expression in primary central nervous system lymphoma of patients with acquired immunodeficiency syndrome. Blood 1997, 90, 1737-1746.

113. Walsh, N.C.; Kenney, L.L.; Jangalwe, S.; Aryee, K.E.; Greiner, D.L.; Brehm, M.A.; Shultz, L.D. Humanized Mouse Models of Clinical Disease. Annu Rev Pathol 2017, 12, 187-215, doi:10.1146/annurev-pathol-052016-100332.

114. Biancotti, J.C.; Town, T. Increasing hematopoietic stem cell yield to develop mice with human immune systems. Biomed Res Int 2013, 2013, 740892, doi:10.1155/2013/740892.

115. Meraz, I.M.; Majidi, M.; Meng, F.; Shao, R.; Ha, M.J.; Neri, S.; Fang, B.; Lin, S.H.; Tinkey, P.T.; Shpall, E.J., et al. An Improved Patient-Derived Xenograft Humanized Mouse Model for Evaluation of Lung Cancer Immune Responses. Cancer Immunol Res 2019, 7, 1267-1279, doi:10.1158/2326-6066.Cir-18-0874.

116. Rongvaux, A.; Willinger, T.; Martinek, J.; Strowig, T.; Gearty, S.V.; Teichmann, L.L.; Saito, Y.; Marches, F.; Halene, S.; Palucka, A.K., et al. Development and function of human innate immune cells in a humanized mouse model. Nat Biotechnol 2014, 32, 364-372, doi:10.1038/nbt.2858. 